\title{
The Unfailing Certainty Of Textbooks
}

William E. Matthews, William Paterson University, USA

\begin{abstract}
A learning objective should describe what students should know or be able to do at the end of the course that they could do before. ${ }^{l}$ The focus of this paper is to look at just three widely utilized models: The Boston Consulting Group Matrix, Break-even Analysis, and McNair's Wheel of Retailing.
\end{abstract}

\section{INTRODUCTION}

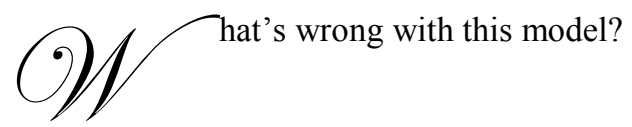

As a university instructor in the management and marketing area, this is a question I ask with some regularity. Invariably, the response is a blank stare. We have, after all, discussed the model and thus should now move on to the next segment of the chapter. One gets the feeling that one has upset the rhythm of the class by asking the students to reflect on the validity of the material.

Business texts usually incorporate a number of basic models or conceptualizations. However, they are invariably presented with a degree of certainty that raises serious questions with regard to the purpose of the text and the appropriate learning objective.

The focus of this paper is to look at just three widely utilized models, namely:

I. The Boston Consulting Group Matrix.

II. Break-even Analysis.

III. McNair's Wheel of Retailing.

And then raise the question: what are/should be the learning objectives? And, by extension, how should these models be presented in the textbooks?

\section{THE BOSTON CONSULTING GROUP (BCG) MATRIX ${ }^{2}$}

\begin{tabular}{|c|c|c|}
\cline { 2 - 3 } $\begin{array}{c}\text { Market Growth } \\
\text { Rate } \\
\text { (\% per year) }\end{array}$ & Stars & $\begin{array}{c}\text { Question } \\
\text { Marks }\end{array}$ \\
\cline { 2 - 3 } & Cash Cows & Dogs \\
\hline
\end{tabular}

\section{Relative Market Share \\ (share relative to largest competitor)}

This is a model/diagram which is invariably accompanied by some attractive graphics and catchy quadrant names. It explains the relationship between the rate of market growth and market position on a company's strategy with regard to various strategic business units (SBUs) in its portfolio. 
For example, a company with a large market share in a rapidly growing market is characterized as a "star" which, as the market growth rate decline, should become a "cash cow" with the potential to spin off funds for investment in other areas of the portfolio. Conversely, a product which has a small market share in a slowly growing market is a "dog" which should (probably) be disposed of.

The model does not point out that:

- A company with a large market share in a slowly growing market (i.e., theoretically a "cash cow") can be "losing its shirt" if it has a high cost structure. In 2005, General Motors lost $\$ 8.6$ billion despite the fact that it still had the largest market share in the United States in a slowly growing market.

- Unless they acquire an existing major player, most firms entering a new market do so with a relatively small market share irrespective of the market's rate of growth.

- $\quad$ A firm's strategy depends very much on (a) its goals and objectives (developed by top management) and (b) the nature of its other product lines.

- A company with a small share of a slowly growing market can be highly profitable if it focuses on a niche within that overall market, etc., etc.

The point is that the model does not, per se, provide an answer to a company's strategy planning. It merely provides a starting point for discussion.

\section{BREAK EVEN ANALYSIS ${ }^{3}$}

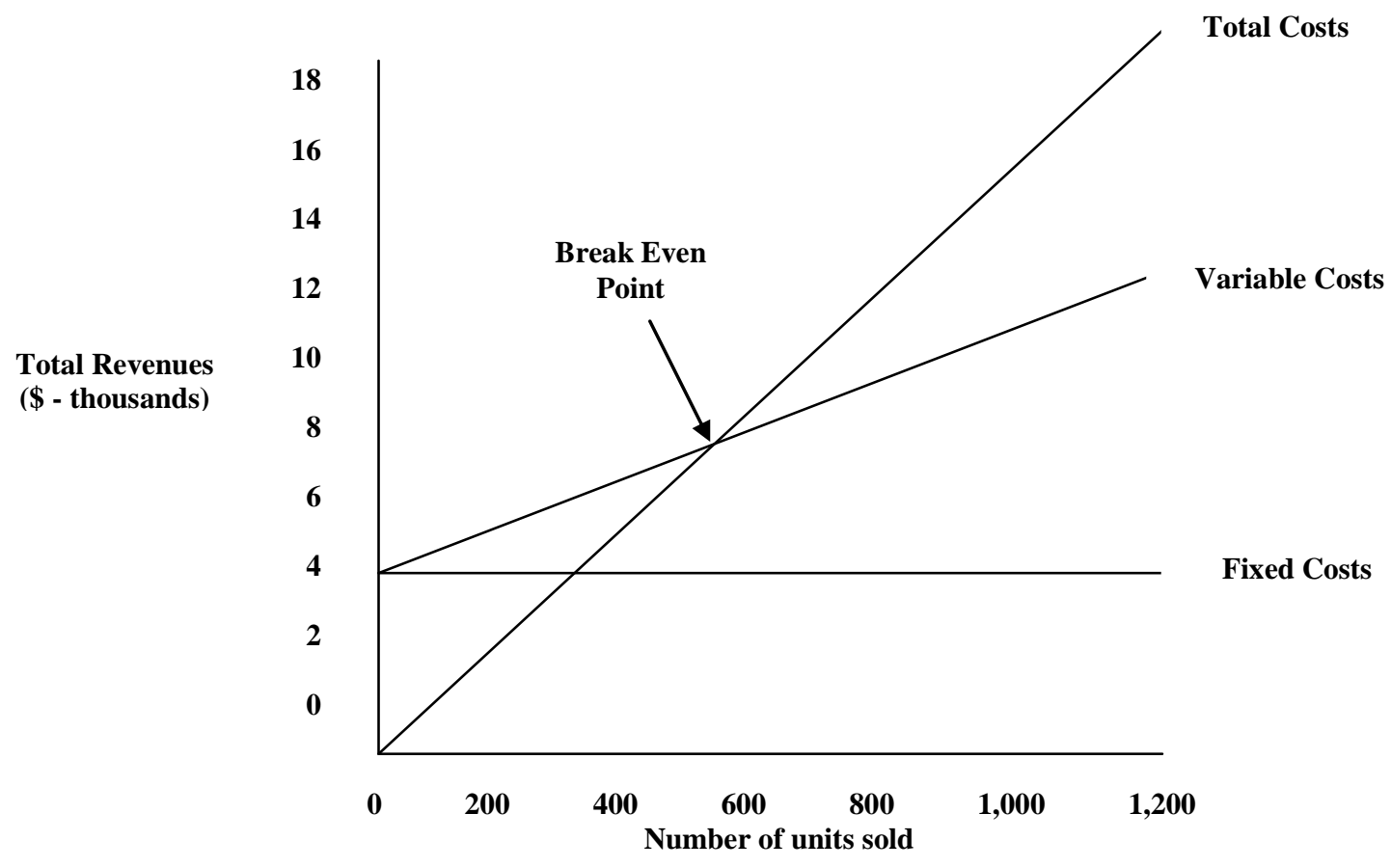

This model (which appears in most economics, management and marketing texts) depicts the calculation of the point at which revenue equals the sum of the fixed and variable costs (i.e., the break-even point). It invariably consists of three impressively straight lines.

However, the text accompanying the model fails to point out that: 
- $\quad$ The fixed costs are fixed only over a range of production levels ... and typically increase step-wise (as equipment requires replacement, a second shift is added, etc.).

- The variable cost per unit does not remain constant as the production volume increases ... it typically declines as the materials purchased declines. The average consumer gets a much better price if they buy a hundred cars than if they buy just one.

- $\quad$ The selling price will rarely remain consist over the entire range of production ... although it may do so if the company pursues a penetration strategy and there is no direct competition. In most cases, the average selling price will decline as different market segments become saturated. The introduction of virtually any high priced consumer electronics is a good example of this.

And probably the most questionable factor:

- If the investment decision is based on the level of annual production then the total capital investment will have to be divided by the length of the useful life of the equipment. What a company chooses as to the "life" of the production facility will potentially have substantial impact on the viability of the project. Try plugging in 1, 5 and 10 years to see the impact on the annual fixed cost.

Again, it provides a starting point for discussion (in terms of orders of magnitude and thus market share targets) not an answer to a company's strategic investment decision.

\section{MCNEIL'S WHEEL OF RETAILING}

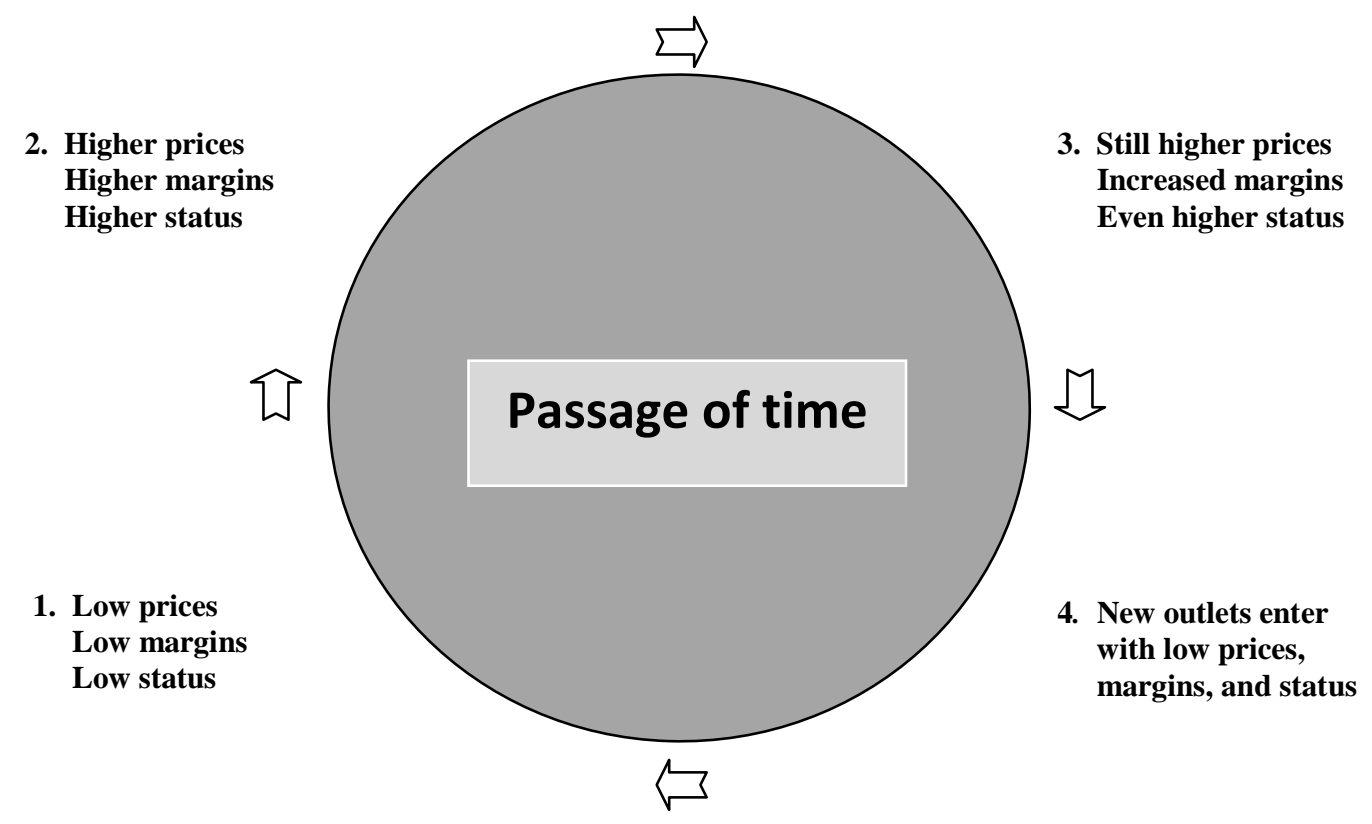

This model, shown in most texts as a complete wheel, is based on the assumption that retail outlets start up as "bare bone" operations in a relatively inexpensive location offering low prices and providing few if any services (such as credit, delivery, support, etc.). As the business prospers, it moves to a better location where it provides a growing range of services ... with a resulting increase in costs and thus prices. This then leaves a "gap" into which a new business can step ... offering low prices and limited services.

There is some merit to the underlying assumption and many examples (such as the fast food business) which support it. As McDonald's and Burger King added new items to their menus, other chains sprang up offering 
a limited menu, low cost product. However, what the model implies (and the text fails to correct) is that retail businesses:

- $\quad$ Always start out as a low cost, low price operation. However, if an entrepreneur wants to offer top quality menswear in a prime downtown location, they begin with that model in mind. They do not start with low priced items in an inexpensive location in the suburbs.

- $\quad$ Continue to move from one position to the next on the wheel. In most cases, this is clearly unlikely. McDonald's provides tasty fast food but it is never likely to morph into a "fine dining experience" with a Maître D' and a sommelier.

- $\quad$ Eventually complete the circle and go from a high priced full-service operation to a low-priced venture in an inexpensive location. Tiffany's is unlikely to revert to selling glass baubles in a strip mall.

- $\quad$ Advance in a single direction around the wheel. Sears, for example, found that it had to reposition itself by moving counter-clockwise to compete effectively with its lower-priced competition, etc.

The above analyses lead to two important questions:

- What are/should be the appropriate learning objectives?

- How should these models be presented in the textbooks?

What are/should be the appropriate learning objectives?

First of all, if texts (and by extension, instructors) merely present these models without any analysis or evaluation then they are implying a degree of certainty that is highly questionable.

However, more important is the question of the learning objectives. Two of the more popular characterizations of learning objectives are the Knowledge-Skills-Attitudes (SKA) model and Bloom's taxonomy. ${ }^{5}$

The SKA model divides the learning objectives according to (a) what students should know and understand by the time the course is completed (knowledge), (b) what students should be able to do by the time the course is completed (skills) and (c) what the students' opinions will be about the subject matter of the course by the time it is completed (attitudes). If all the text (and the instructor) is presenting is the model itself then it difficult to see that the typical student will progress past understanding the structure and intent of the model.

Bloom's taxonomy divides the learning objectives into six levels: knowledge, comprehension, application, analysis, synthesis, and evaluation. Against this measure, the typical text certainly satisfies the lowest level of cognitive learning (i.e., knowledge and the recall of data or information). However, it is doubtful if the typical student reaches the next level (i.e., comprehension). The term is defined in a various ways. However, if one accepts that comprehension is "the ability to understand the meaning or importance of something" then even this is highly unlikely to be achieved.

One has to ask: is that what we are trying to achieve? Is our goal to merely enable students who can remember the facts long enough to correctly answer a series of multiple choice questions? Or are we trying to assist students to achieve higher levels of the cognitive taxonomies?

\section{How should these models be presented in the textbooks?}

These models can be presented in textbooks in three different ways:

- $\quad$ As is ... with no commentary as to its strengths and weaknesses.

- As is ... but with the notation that it provides a basis for discussion nature and is not "carved in stone."

- Accompanied by a statement of the issues that may well be raised as to its strengths and weaknesses and thus to its utility. 
The first option leaves any discussion of its strengths and weaknesses up to the instructor and, if he/she sees no problems with the model, leaves students with (a) the perception that it is a sound statement of fact and (b) the ability to do nothing more than regurgitate the key elements on a test (i.e., the basic level of any taxonomy).

The second option is somewhat better in that it alerts students to the fact that the model is merely a starting point for any analysis. It is then up to the instructor to decide to what extent, if any, they wish to explore the realities of the model.

The third option provides students with a far better understanding of the utility of the model and its utilization in the real world (i.e., it provides a basis for them to evaluate the model in terms of higher levels of any taxonomy). However, it raises a separate issue, namely; are we suggesting to students that models presented in a text are not "carved in stone" and thus doing them a disservice by introducing a degree of uncertainty?

\section{CONCLUSION}

The three models described in this paper have value in that they provide a basis for thinking. However, it is important for students to recognize that they do not provide answer to business situations just a method for addressing them. Their value lies in their use as a starting point and in the stimulation of discussion. And this element should, in my opinion, be introduced either in the text itself or by the instructor.

A management team using any one of these three models would not (hopefully) slavishly follow the model. It would use it to explore whether or not it had value in terms of their current and specific situation and whether it facilitates their analysis. The answer may well be "no." And one has to ask whether we do our students a disservice by implying otherwise.

\section{NOTES/REFERENCES}

1. MIT Teaching and Learning Laboratory - Learning Objectives. Http://web.mit/tll/teachingmaterials/learning-objectives/index.html.

2. In the early 1970s, the Boston Consulting Group (BCG) developed a model for managing a portfolio of different business units (or major product lines). The BCG growth-share matrix displays the various business units on a $2 \times 2$ matrix of the market growth rate versus market share to competitors. While it remains the most popular of the models, there are others. For example, the McKinsey matrix/General Electric matrix which consists of a $3 \times 3$ grid and replaces rate of market growth with market/industry attractiveness replaces market growth as the dimension of industry attractiveness. Competitive strength replaces market share as a measure of the competitive position of each business unit.

3. Break-even analysis. This is one of the most common tools used in evaluating the economic feasibility of a new enterprise or product.

4. Malcolm P. McNair, "Significant Trends and Development in the Postwar Period" in A.B. Smith, ed. Competitive Distribution in a Free, High Level Economy and Its Implications for the University (Pittsburgh: University of Pittsburgh Press, 1958), pp. 1-25. It might be noted that there is some debate as to whether McNair actually suggested this pattern of development or whether it (and subsequent diagrams) were attributed to him.

5. Benjamin S. Bloom, Taxonomy of Educational Objectives, Handbook I: The Cognitive Domain (New York: David McKay Co Inc., 1956). 
NOTES 